\title{
Singlet oxygen quantum yields from halogenated chlorins: potential new photodynamic therapy agents
}

\author{
Marta Pineiro, Mariette M. Pereira, A.M.d'A. Rocha Gonsalves, \\ Luis G. Arnaut*, Sebastião J. Formosinho ${ }^{1}$ \\ Chemistry Department, University of Coimbra, 3049 Coimbra Codex, Portugal
}

Received 25 July 2000; received in revised form 1 September 2000; accepted 2 October 2000

\begin{abstract}
Flash photolysis and photoacoustic calorimetry were used to measure the energy-transfer rates and singlet oxygen quantum yields originated by the triplet states of halogenated tetrakisphenylporphyrins and related chlorins in aerated toluene. The chlorins $\left(\lambda_{\text {max }} \approx\right.$ $\left.660 \mathrm{~nm}, \varepsilon \approx 3 \times 10^{4} \mathrm{M}^{-1} \mathrm{~cm}^{-1}\right)$ have long-lived triplet states $(>12 \mu \mathrm{s})$ in the absence of molecular oxygen, and in its presence the singlet oxygen production quantum yields of the 2-chloro and 2,6-dichlorophenyl derivatives are $0.89 \pm 0.05$ and $0.98 \pm 0.02$, respectively. The high absorptivity in the red, the photostability and the efficiency of these chlorins in producing singlet oxygen suggests a ground for the development of better sensitisers for photodynamic therapy. (c) 2001 Elsevier Science B.V. All rights reserved.
\end{abstract}

Keywords: Photoacoustic calorimetry; Chlorin; Singlet oxygen; Sensitisers; Photodynamic therapy

\section{Introduction}

The synthesis and photochemical characterisation of porphyrins and other tetrapyrrolic macrocycles has been actively pursued in recent years [1-4]. This type of compounds serves to harvest light in natural and synthetic devices, and their use in molecular electronics $[5,6]$, catalysis [7] and photodynamic therapy (PDT) [8-11], has attracted much interest.

An important landmark in the development of PDT sensitisers was the approval of Photofrin, in 1993, for the treatment of certain cancers [12]. Photofrin is a commercial preparation of haematoporphyrin derivative $(\mathrm{HpD})$ and fulfils, to some extent, the criteria for a good sensitiser. However, it is a complex and variable mixture including monomers, dimers and oligomers of porphyrins that may aggregate to different extents in different environment with resultant alterations in biological efficacy. Furthermore, appreciable amounts of $\mathrm{HpD}$ are retained in the skin, causing skin sensitivity for some weeks following treatment [13]. Finally, the lowest energy wavelength maximum (Band I) of $\mathrm{HpD}$ occurs at $630 \mathrm{~nm}$ with a modest extinction coefficient (ca. $3000 \mathrm{M}^{-1} \mathrm{~cm}^{-1}$ for the monomer and slightly lower for the aggregates) [14].

\footnotetext{
* Corresponding author.

${ }^{1}$ Also at Escola Superior de Ciâncias e Tecnologia, Universidade Católica Portuguesa, 3500 Viseu (Portugal).
}

Improved tumour photosensitisers have been actively pursued. The new generation photosensitisers include halogenated porphyrins, [1] chlorins [15] and phthalocyanines [16] some of them have been accepted by WHO [12].

A major shortcoming of the porphyrins is their weak absorption in the red. However, taking into account that the penetration depth of light in mammalian tissues increases by a factor of about 2 going from 630 to $800 \mathrm{~nm}$ [9], it is advantageous to reduce the porphyrin to the corresponding chlorin or bacteriochlorin which absorb further into the red. Bonnett et al. $[3,11,15]$ developed hydroxyphenyl-substituted porphyrins, chlorins and bacteriochlorins with remarkable tumour photonecrosis activity.

Better PDT sensitisers should retain the convenient chemical properties of porphyrins, such as easy synthesis and isolation, photostability and efficient energy transfer to the ground state of molecular oxygen. Chlorins are good candidates because they are relatively stable in solution and absorb 10 times more light in the phototerapeutic window than the corresponding porphyrins. Bacteriochlorins are another possibility but they were reported as relatively unstable in solution $[11,17]$. The development of new methods for chlorins synthesis and isolation is therefore crucial in this filed. At present, the vast majority of chlorins are produced by addition reactions on ring $\mathrm{D}$ of porphyrins or starting from substituted pyrroles, using complex synthetic process, giving generally poor yields and complex mixtures of products $[18,19]$. 


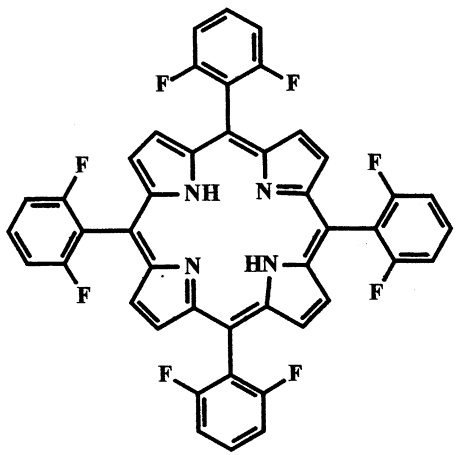

TDFPP

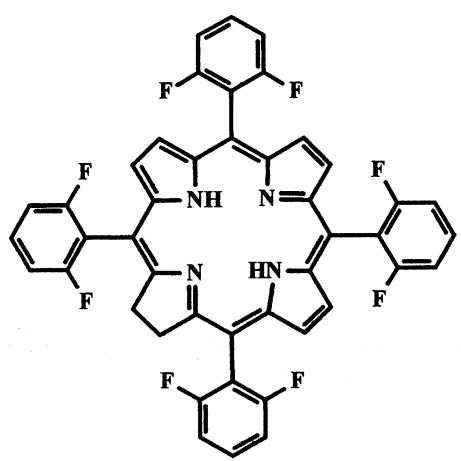

TDFPC

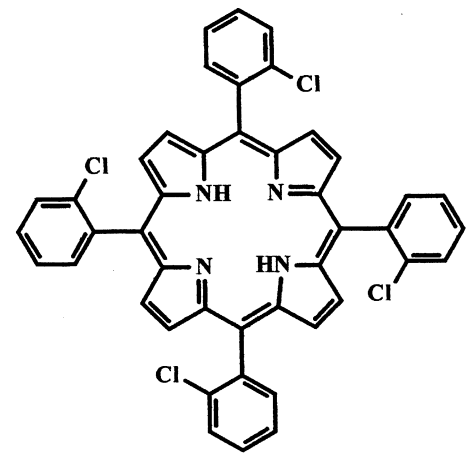

ToCPP

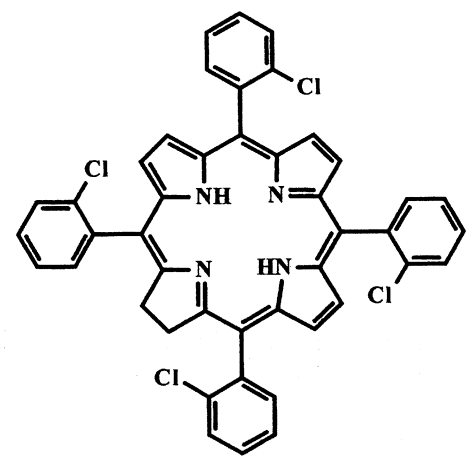

ToCPC

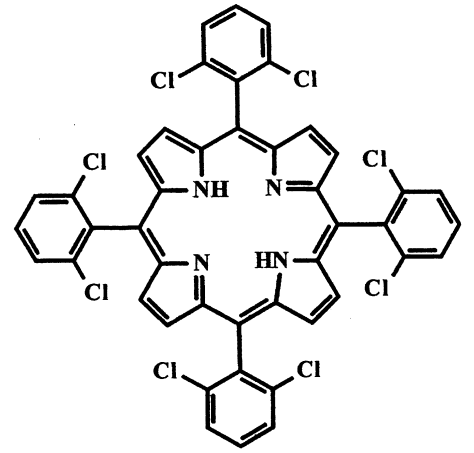

TDCPP

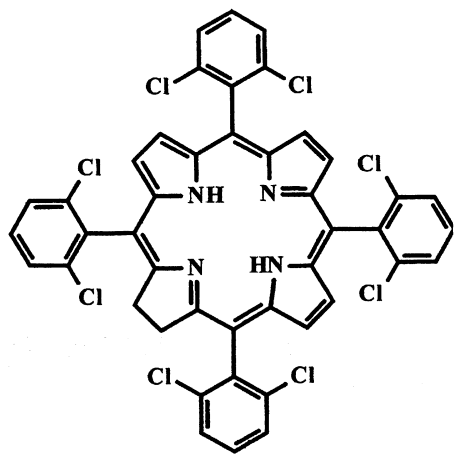

TDCPC

Fig. 1. Porphyrins and chlorins studied in this paper. TDFPP, 5,10,15,20-tetrakis(2,6-difluorophenyl)porphyrin; ToCPP, 5,10,15,20-tetrakis(2-chlorophenyl)porphyrin; TDCPP, 5,10,15,20-tetrakis(2,6-dichlorophenyl)porphyrin; TDFPC, 5,10,15,20-tetrakis(2,6-difluorophenyl)chlorin; ToCPC, 5,10,15,20tetrakis(2-chlorophenyl)chlorin; TDCPC, 5,10,15,20-tetrakis(2,6-chlorophenyl)chlorin.

We describe in this paper a strategy allowing the preparation of chlorins in a single step in high yields and from simple porphyrins also prepared in one step. The method is applied to the synthesis of 5,10,15,20-tetrakisphenylchlorins having chlorine and fluorine atoms in the ortho positions. These chlorins are shown in Fig. 1, together with the porphyrins from where they were synthesised. The isolation and full characterisation of these chlorins are reported. We investigated their photophysical and photochemical properties using flash photolysis and time-resolved photoacoustic calorimetry (PAC), and measured triplet lifetimes, energy-transfer rates and singlet oxygen quantum yields $\left(\Phi_{\Delta}\right)$. These chlorins were selected because we recently showed that halogenated metalloporphyrins have $\Phi_{\Delta} \approx 1$ [1]. To the best of our knowledge, the halogenated chlorins reported in this work are novel compounds.

\section{Experimental}

\subsection{Instrumentation}

${ }^{1}$ H NMR spectra were recorded on $300 \mathrm{MHz}$ Bruker-AMX spectrometer. Mass spectra were obtained on a VG autospec and elemental analysis on EA1108-CHNS-0 Fisons Instru- ments. Absorption spectra were recorded with Shimadzu UV-2100 spectrophotometer. Fluorescence and phosphorescence spectra were measured with a Spex Fluorolog 3 spectrophotometer, with correction for the wavelength dependence of the detection system (RCA C31034 photomultiplier and the 1934D3 module for phosphorimetry). Flash photolysis employed an Applied Photophysics LKS.60 laser flash photolysis spectrometer, with a Spectra-Physics Quanta-Ray GCR-130 Nd:YAG laser and a Hewlett-Packard Infinium Oscilloscope $\left(1 \mathrm{MS} \mathrm{s}^{-1}\right)$; the samples were irradiated with the second-harmonic of the laser and the monitoring white light was produced by a $150 \mathrm{~W}$ pulsed Xe lamp; the detection of the transient spectra in the $200-850 \mathrm{~nm}$ range was made with Hamamatsu 1P28 and R928 photomultipliers.

Time-resolved PAC measurements were performed in a homemade apparatus following the front-face irradiation design described by Arnaut et al. [20] and discussed in detail elsewhere [1,21,22]. Briefly, we use a PTI $\mathrm{N}_{2}$ laser (model PL2300) working at a frequency of $2 \mathrm{~Hz}$ to pump a PTI dye laser (model PL202) and irradiate the solutions flown through a $0.11 \mathrm{~mm}$ photoacoustic cell. The energy of the $\mathrm{N}_{2}$ laser is $1 \mathrm{~mJ} /$ pulse, and the energy of the dye laser is about half of that value. The photoacoustic waves are detected by a $2.25 \mathrm{MHz}$ Panametrics transducer (model A106S), 
pre-amplified (Panametrics ultrasonic pre-amplifier, model 5676), captured by a digital storage oscilloscope (Tektronix DSA601, $1 \mathrm{GS} \mathrm{s}^{-1}$, two channels) and transferred to a computer for analysis. Porphyrins and chlorins were irradiated at $421 \mathrm{~nm}$ using Mn-TPP as calorimetric reference. Additionally, the chlorins were also irradiated at the $\mathrm{Q}_{x}(0-0)$ band (ca. $660 \mathrm{~nm}$ ) using azulene as calorimetric reference.

Fluorescence quantum yields were measured according to published procedures $[1,23]$. Fluorescence excitation spectra were obtained for all the porphyrins and chlorins and agreed well with the corresponding absorption spectra. The phosphorescence studies were conducted in toluene at liquid nitrogen temperature. The solutions were carefully de-aerated with $\mathrm{N}_{2}$ previously saturated in toluene. The excitation was in the Soret band.

Flash photolysis of air- and $\mathrm{N}_{2}$-saturated solutions with absorbance between 0.2 and 0.4 at the Soret band employed the second harmonic of the Nd:YAG laser $(532 \mathrm{~nm}, 80 \mathrm{~mJ}$, $8 \mathrm{~ns}$ fwhm). Triplet-triplet absorption spectra were obtained for all porphyrins and chlorins. Their decays at 320 and $460 \mathrm{~nm}$ were followed in the presence and absence or air and fitted with one exponential.

\subsection{Materials and synthesis}

All solvents and reagents (Aldrich) were purified by standard methods before used. The chloroform used in the preparative thin layer chromatography was neutralised with neutral active alumina.

The porphyrins employed in these studies were synthesised according to the procedures described elsewhere $[1,24]$. The characterisation is in agreement with the description therein.

General chlorine synthesis: The porphyrin $(0.1 \mathrm{mmol})$ and sodium carbonate $(22 \mathrm{mg}, 0.16 \mathrm{~mol})$ were dissolved in $50 \mathrm{ml}$ of freshly distilled $\alpha$-picoline, and the temperature raised to $120^{\circ} \mathrm{C}$. A solution of $p$-toluenesulphonylhydrazine also in $\alpha$-picoline $(10 \mathrm{ml}, 0.08 \mathrm{M})$ was added to the reaction mixture. The reaction was followed by UV-Vis spectroscopy and the temperature raised until the absorption band at $750 \mathrm{~nm}$ (typical of bacteriochlorins) could be detected. After cooling, $50 \mathrm{ml}$ of water was added and the precipitate filtrated. The product was chromatographed in silica thick layer, using chloroform $/ n$-hexane $(1 / 1)$. The layer corresponding to the chlorine was recovered, the silica was washed with chloroform and the chlorine recrystallised from chloroform $/ n$-hexane. Yields and characterisation are presented below.

\subsection{Characterisation}

5, 10,15, 20- Tetrakis(2, 6- difluorophenyl)chlorin. Yield: $45 \% ;{ }^{1} \mathrm{H}$ NMR $\left(300 \mathrm{MHz}, \mathrm{CDCl}_{3}\right): \delta=8.63(\mathrm{~d}, 2 \mathrm{H}, J=$ $4.8 \mathrm{~Hz}), 8.44(\mathrm{~s}, 2 \mathrm{H}), 8.29(\mathrm{~d}, 2 \mathrm{H}, J=4.8 \mathrm{~Hz}), 7.77-7.62$ (m, 4H), 7.34-7.29 (m, 8H), $4.25(\mathrm{~s}, 4 \mathrm{H}),-1.42(\mathrm{~s}, 2 \mathrm{H})$; MS
(FAB): $m / z=760$ (molecular ion); $\mathrm{C}_{44} \mathrm{H}_{24} \mathrm{~N}_{4} \mathrm{~F}_{8}$ : calcd. $\mathrm{C}$ 69.47, H 3.18, N 7.37; found C 69.89, H 3.98, N 7.78.

5,10,15,20-Tetrakis(2-chlorophenyl)chlorin. Yield: 51\%; ${ }^{1} \mathrm{H} \mathrm{NMR}\left(300 \mathrm{MHz}, \mathrm{CDCl}_{3}\right): \delta=8.45(\mathrm{~d}, 2 \mathrm{H}, J=4.9 \mathrm{~Hz})$, $8.28(\mathrm{~s}, 2 \mathrm{H}), 8.09(\mathrm{~d}, 2 \mathrm{H}, J=4.9 \mathrm{~Hz}), 7.98-7.95(\mathrm{~m}$, $4 \mathrm{H}), 7.80-7.56(\mathrm{~m}, 12 \mathrm{H}), 4.12(\mathrm{~s}, 4 \mathrm{H}),-1.40(\mathrm{~s}, 2 \mathrm{H})$; MS (FAB): $m / z=750-758$ (Cl isotopes for molecular ion); $\mathrm{C}_{44} \mathrm{H}_{28} \mathrm{~N}_{4} \mathrm{Cl}_{4}$ : calcd. C 70.04, H 3.74, N 7.43; found C 70.12, H 3.69, N 7.44.

5,10,15,20-Tetrakis(2,6-dichlorophenyl)chlorin. Yield: $28 \% ;{ }^{1} \mathrm{H}$ NMR $\left(300 \mathrm{MHz}, \mathrm{CDCl}_{3}\right): \delta=8.46(\mathrm{~d}, 2 \mathrm{H}, J=$ $4.7 \mathrm{~Hz}), 8.27(\mathrm{~s}, 2 \mathrm{H}), 8.09(\mathrm{~d}, 2 \mathrm{H}, J=4.7 \mathrm{~Hz}), 7.81-7.71$ (m, 8H), 7.65-7.56 (m, 4H), $4.10(\mathrm{~s}, 4 \mathrm{H}),-1.32(\mathrm{~s}, 2 \mathrm{H})$; MS (FAB): $m / z=888-898(\mathrm{Cl}$ isotopes for molecular ion); $\mathrm{C}_{44} \mathrm{H}_{24} \mathrm{~N}_{4} \mathrm{Cl}_{8}$ : calcd. C 59.23, H 2.71, $\mathrm{N} 6.28$; found C 59.40, H 2.79, N 6.17 .

\section{Results}

\subsection{Synthesis}

Aromatic meso-substituted porphyrins were prepared by condensation of appropriate aromatic aldehydes with pyrrole in nitrobenzene/acetic acid using the method of Gonsalves et al. [24]. The porphyrins were then reduced with diimide using Whitlock's method [25], performing innovations in the reaction conditions and isolation method (Fig. 2). The chlorins were synthesised by reduction of porphyrins with diimide (prophyrin/diimide 1/8) generated in situ by at once addition of $p$-toluenesulphonylhydrazine and $\mathrm{K}_{2} \mathrm{CO}_{3}$, using $\alpha$-picoline as solvent. The reaction was monitored by UV-Vis spectroscopy. When the typical absorption band of bacteriochlorins was observed $(\approx 750 \mathrm{~nm})$ about $65 \%$ of the corresponding chlorins was measured by UV-Vis. No significant differences related to the structural differences on the porphyrin skeleton were found on the reactivity. Isolated yields of 45,51 and $28 \%$ were obtained for 5,10,15, 20-tetrakis(2,6-difluorophenyl)chlorin, 5,10,15,20-tetrakis(2-chlorophenyl)chlorin and 5,10,15,20-tetrakis(2,6-chlorophenyl)chlorin, respectively. The poor yield obtained for the TDCPC originated on its poor solubility and consequent difficult work up.

\subsection{Photophysics and photochemistry}

We show in Fig. 3 the absorption spectra of porphyrins and the corresponding chlorins. The free-base porphyrins have the characteristic spectra of the etio type. The chlorins have a strong absorvance in the red with a $\lambda_{\max } \approx 650 \mathrm{~nm}$. We obtained the absorption coefficients of the bands from the Beer-Lambert law using solutions with concentrations in the $10^{-4}-10^{-7} \mathrm{M}$ range, Table 1.

Fig. 3 also shows the fluorescence spectra of free-base porphyrins and chlorins. All spectra show the $\mathrm{Q}(0-0)$ and $\mathrm{Q}(0-1)$ emission bands typical of porphyrins [26]. The Stokes shift 


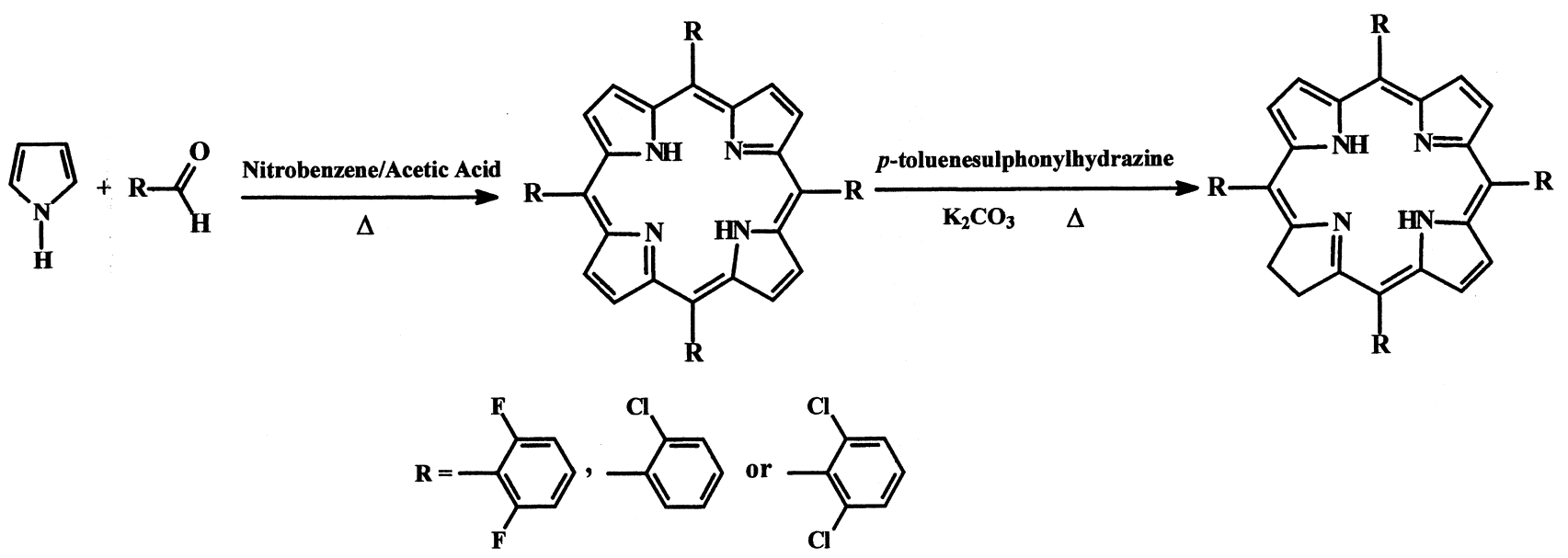

Fig. 2. General procedure of porphyrin synthesis and reduction to chlorins.

of these compounds is very small and the spectroscopic energies, calculated from the intersection of the normalised absorption and fluorescence spectra of the $\mathrm{Q}_{x}(0-0)$ band, are nearly identical to the relaxed energies of the singlet state. Table 1 presents the position of the bands, Stokes shifts, lowest excited singlet energies $\left(E_{\mathrm{s}}\right)$ and the fluorescence quantum yields $\left(\Phi_{\mathrm{F}}\right)$. We were unable to detect TPP phosphorescence at $77 \mathrm{~K}$ with our phosphorimeter. The literature registers a phosphorescence quantum yield of $\Phi_{\mathrm{P}}=$ $4 \times 10^{-5}$ [27]. Interestingly, we obtained a nice phosphorescence spectrum of 9-fluorenone $\left(\Phi_{\mathrm{P}}=3 \times 10^{-5}\right)$ with a maximum at $572 \mathrm{~nm}$. Admittedly, the sensitivity of our equipment decreases from 572 to $800 \mathrm{~nm}$. We were also un- able to detect the phosphorescence of the halogenated porphyrins and chlorins reported in this study.

Porphyrin and chlorin triplet lifetimes in toluene solutions were measured by flash photolysis in the presence of air- and in $\mathrm{N}_{2}$-saturated solutions, Table 2 . The triplet lifetimes in $\mathrm{N}_{2}$-saturated solutions are limited by insufficient de-aeration and by the diffusion of $\mathrm{O}_{2}$ into the solutions. However, the values measured under our experimental conditions are sufficiently long not to introduce significant errors in the determination of energy-transfer rates and singlet oxygen quantum yields. A typical triplet-triplet absorption spectrum and its decay are shown in Fig. 4(a) and (b), respectively, using TDCPC as example. The triplet-triplet

Table 1

Absorption and luminescence data of porphyrins and chlorins in de-aerated toluene solutions

\begin{tabular}{|c|c|c|c|c|c|c|c|c|c|c|}
\hline & \multicolumn{5}{|c|}{ Absorption $\left(\lambda_{\max }(\mathrm{nm}), \varepsilon\left(\mathrm{M}^{-1} \mathrm{~cm}^{-1}\right)\right)$} & \multicolumn{2}{|c|}{ Fluorescence $\lambda(\mathrm{nm})$} & \multirow[t]{2}{*}{ Stokes shift $\left(\mathrm{cm}^{-1}\right)$} & \multirow[t]{2}{*}{$E_{\mathrm{S}}\left(\mathrm{kcal} \mathrm{mol}^{-1}\right)$} & \multirow[t]{2}{*}{$\Phi_{\mathrm{F}}$} \\
\hline & $\mathrm{B}(0-0)$ & $\mathrm{Q}_{y}(1-0)$ & $\mathrm{Q}_{y}(0-0)$ & $\mathrm{Q}_{x}(1-0)$ & $\mathrm{Q}_{x}(0-0)$ & $\mathrm{Q}(0-0)$ & $\mathrm{Q}(0-1)$ & & & \\
\hline TDFPC & 410, 1.34E5 & $510,1.11 \mathrm{E} 4$ & $536,3.92 \mathrm{E} 3$ & $601,4.40 \mathrm{E} 3$ & $655,3.99 \mathrm{E} 4$ & 658 & 719 & 69.61 & $43.60 \pm 0.09$ & $0.124 \pm 0.026$ \\
\hline ТoСРC & $418,1.20 \mathrm{E} 5$ & $515,1.17 \mathrm{E} 4$ & $539,5.46 \mathrm{E} 3$ & $602,4.15 \mathrm{E} 3$ & $655,3.89 \mathrm{E} 4$ & 657 & 718 & 46.47 & $43.66 \pm 0.04$ & $0.089 \pm 0.018$ \\
\hline TDCPC & $418,7.82 \mathrm{E} 4$ & $513,7.46 \mathrm{E} 3$ & $540,2.61 \mathrm{E} 3$ & $604,2.02 \mathrm{E} 3$ & $660,2.58 \mathrm{E} 4$ & 661 & 706 & 22.92 & $43.36 \pm 0.01$ & $0.049 \pm 0.022$ \\
\hline TDFPP & $416,2.80 \mathrm{E} 5$ & $509,2.11 \mathrm{E} 4$ & $539,2.72 \mathrm{E} 3$ & $587,5.89 \mathrm{E} 3$ & $655,5.28 \mathrm{E} 3$ & 657 & 713 & 46.47 & $43.64 \pm 0.05$ & $0.069 \pm 0.015$ \\
\hline ТoСРP & $418,3.14 \mathrm{E} 5$ & $512,2.13 \mathrm{E} 4$ & $541,4.99 \mathrm{E} 3$ & $588,6.49 \mathrm{E} 3$ & $655,7.09 \mathrm{E} 3$ & 657 & 716 & 46.47 & $43.66 \pm 0.04$ & $0.023 \pm 0.007$ \\
\hline TDCPP & $418,1.18 \mathrm{E} 5$ & $513,7.08 \mathrm{E} 3$ & $540,3.70 \mathrm{E} 3$ & $589,3.30 \mathrm{E} 3$ & $660,2.05 \mathrm{E} 3$ & 661 & 719 & 22.92 & $43.33 \pm 0.02$ & $0.005 \pm 0.002$ \\
\hline
\end{tabular}

Table 2

Triplet lifetimes and quantum yields in toluene measured by flash photolysis and photoacoustic calorimetry, respectively ${ }^{\mathrm{a}}$

\begin{tabular}{lcclllll}
\hline & $\tau_{\mathrm{T}}\left(\mathrm{N}_{2}\right)(\mu \mathrm{s})$ & $\tau_{\mathrm{T}}($ air) $(\mathrm{ns})$ & $\begin{array}{l}k_{\mathrm{q}} \times 10^{-9} \\
\left(\mathrm{M}^{-1} \mathrm{~s}^{-1}\right)\end{array}$ & $\begin{array}{l}\phi_{1}\left(\mathrm{~N}_{2}\right) \\
(\lambda=421 \mathrm{~nm})\end{array}$ & $\begin{array}{l}\phi_{2} \text { (air) } \\
(\lambda=421 \mathrm{~nm})\end{array}$ & $\begin{array}{l}\Phi_{\Delta} \\
(\lambda=421 \mathrm{~nm})\end{array}$ & $\begin{array}{l}\Phi_{\Delta}(\lambda=655 \\
\text { or } 660 \mathrm{~nm})\end{array}$ \\
\hline TDFPC & 5.0 & $305.4 \pm 4.7$ & $1.80 \pm 0.03$ & $0.4936 \pm 0.020$ & $0.1454 \pm 0.007$ & $0.85 \pm 0.03$ \\
ToCPC & 6.1 & $351.8 \pm 3.8$ & $1.57 \pm 0.02$ & $0.5019 \pm 0.016$ & $0.1364 \pm 0.007$ & $0.92 \pm 0.04$ \\
TDCPC & 8.2 & $392.7 \pm 5.8$ & $1.41 \pm 0.02$ & $0.5134 \pm 0.026$ & $0.1375 \pm 0.003$ & $0.93 \pm 0.05$ & $0.89 \pm 0.04$ \\
TDFPP & 16.6 & $492.5 \pm 2.2$ & $1.12 \pm 0.01$ & $0.5242 \pm 0.015$ & $0.1534 \pm 0.006$ & $0.84 \pm 0.04$ \\
ToCPP & 11.6 & $495.2 \pm 3.5$ & $1.12 \pm 0.01$ & $0.4903 \pm 0.020$ & $0.1837 \pm 0.004$ & $0.94 \pm 0.06$ \\
TDCPP & 16.5 & $641.0 \pm 10.3$ & $0.86 \pm 0.02$ & $0.5827 \pm 0.021$ & $0.090 \pm 0.005$ & $0.98 \pm 0.04$ \\
\hline
\end{tabular}

a The uncertainties of PAC experiments were calculated for a 95\% confidence level; the value of $\tau_{\mathrm{T}}\left(\mathrm{N}_{2}\right)$ is a lower limit, because some residual $\mathrm{O}_{2}$ may remain in solution after $\mathrm{N}_{2}$ purging. 

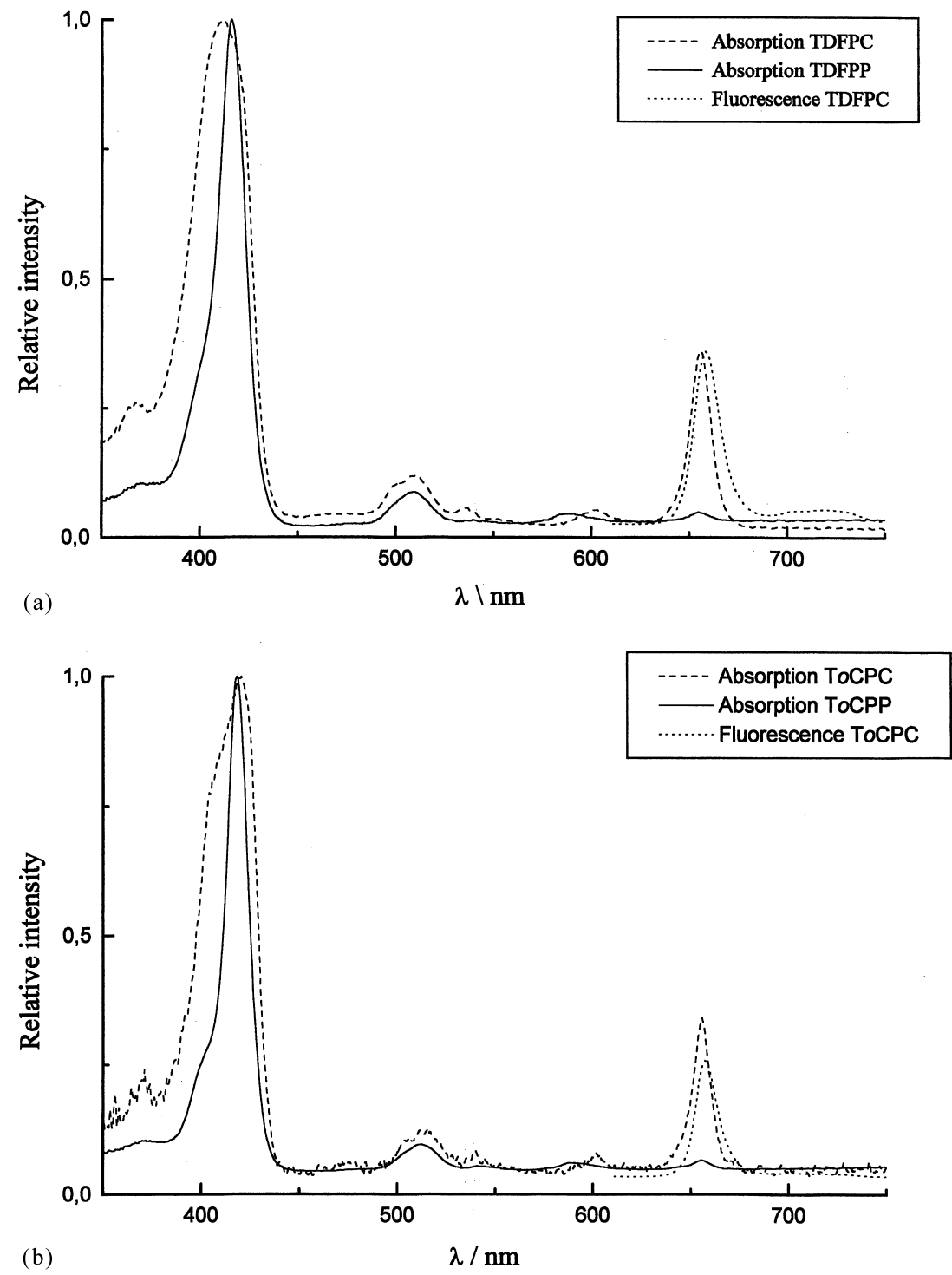

(b)

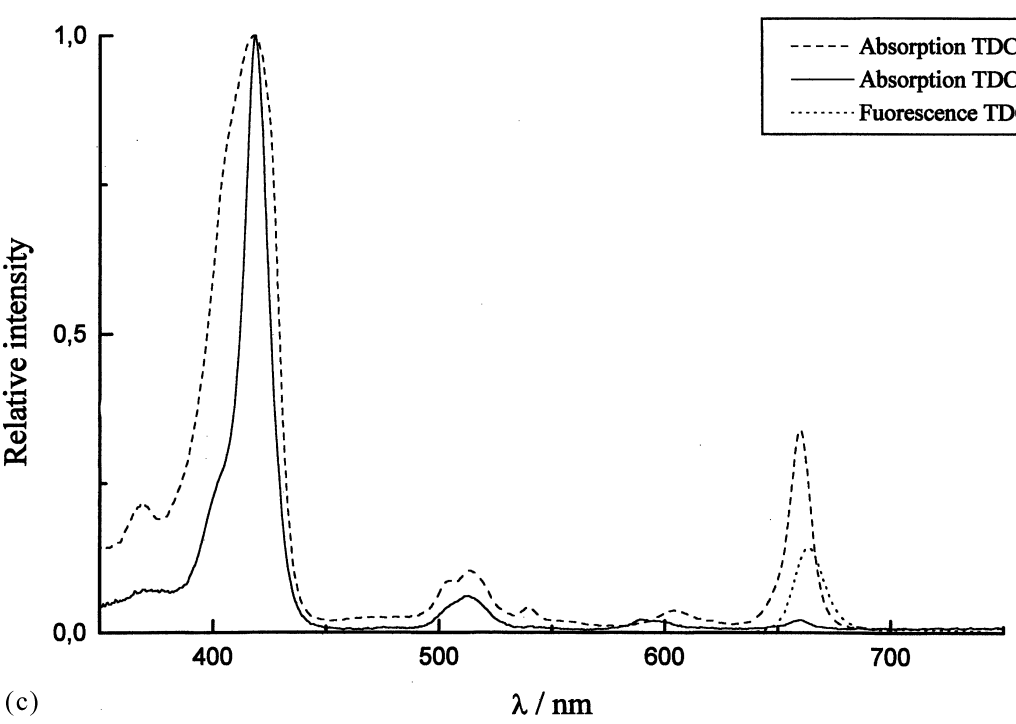

Fig. 3. Absorption and fluorescence emission spectra of porphyrins (solid lines) and their corresponding chlorins (dashed lines). The absorption spectra were normalised to 1.0 at their respective Soret band. The fluorescence spectra (dotted lines) were scaled to the same quantity of light absorbed. (a) TDFPP and TDFPC; (b) ToCPP and ToCPC; (c) TDCPP and TPCPC. 


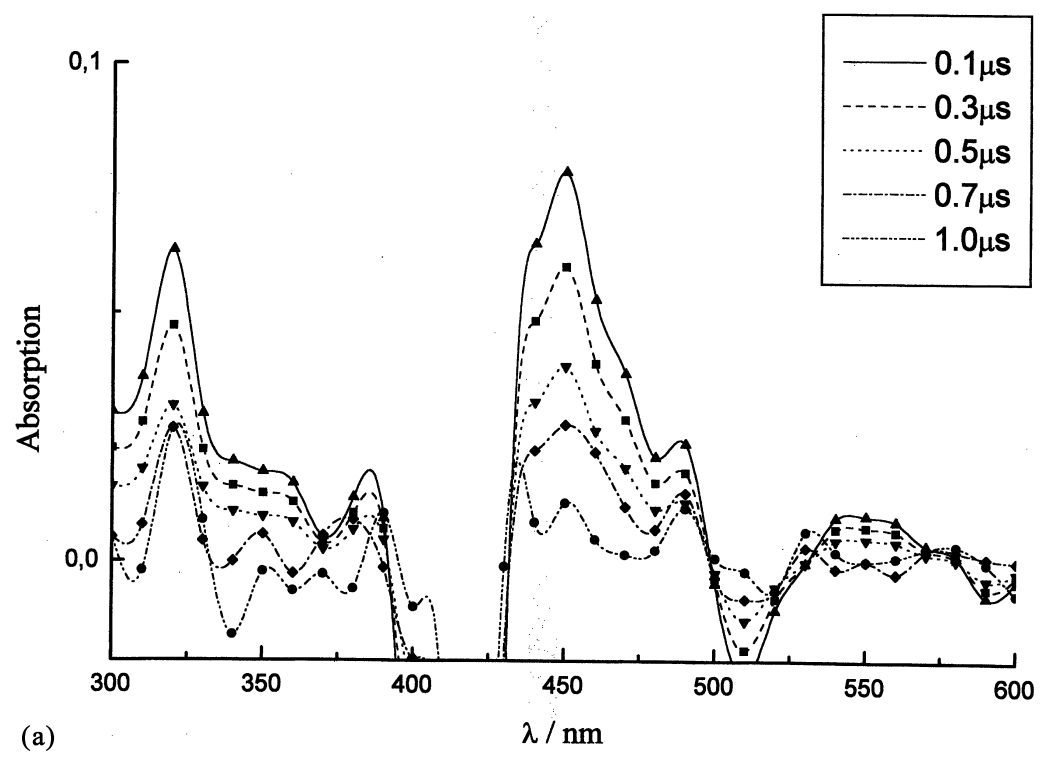

(a)

$\lambda / \mathrm{nm}$

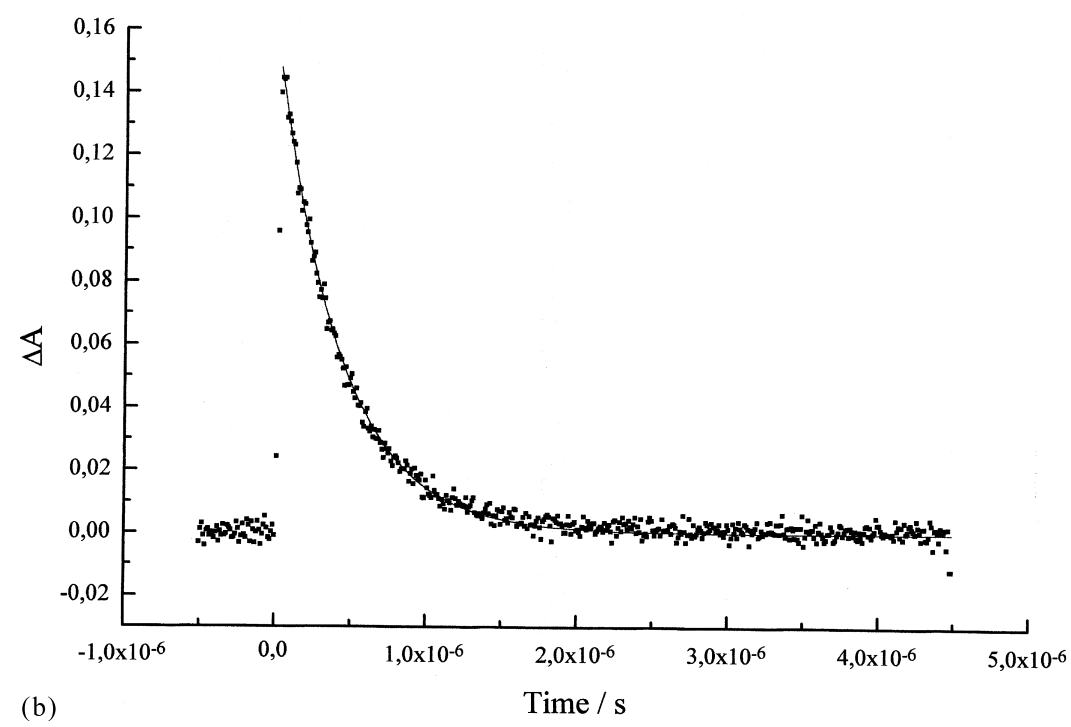

Fig. 4. (a) Triplet-triplet absorption spectrum of TDCPC and (b) analysis of its decay at $460 \mathrm{~nm}$. The chlorin was irradiated at $532 \mathrm{~nm}$. The decay was fitted with a single exponential.

absorption spectra of the other halogenated chlorins closely resemble that of Fig. 4, with maxima at 340 and $450 \mathrm{~nm}$.

Time-resolved PAC measurements with irradiation at $421 \mathrm{~nm}$ employed Mn-TPP as calorimetric reference. Mn-TPP absorption at 650 or $655 \mathrm{~nm}$ is too weak for a convenient photoacoustic reference. Azulene (longest wavelength absorption maximum at $575 \mathrm{~nm}$ ) has a singlet-state lifetime of $7 \mathrm{ps}$, a fluorescence quantum yield from the $S_{1}$ state of about $10^{-6}$ [28] and was previously used as calorimetric reference in polar solvents [29]. We tested the linearity of the calorimetric response of azulene with the laser intensity and fraction of light absorbed against that of Mn-TPP and $\beta$-carotene at $500 \mathrm{~nm}$ and found that they are identical. Thus, we conclude that azulene is a suitable photoacoustic reference for studies in the $500-700 \mathrm{~nm}$ range.

PAC followed our protocol for PAC measurements [1,21]. At a given laser intensity, we acquire and average 100 acoustic waves of the calorimetric reference ( $\mathrm{T}$-wave), and repeat this procedure until four sets of consistent $\mathrm{T}$-waves are obtained. Then, we do the same for a porphyrin or chlorine solution with the same absorptivity as the reference solution at the irradiation wavelength, and obtain four sets of waves (E-wave), each one of them being the average of 100 acoustic waves. We repeat this procedure one more time with the pure solvent (toluene) to obtain four sets of the background signal (O-wave). Fig. 5 shows typical raw data obtained in 


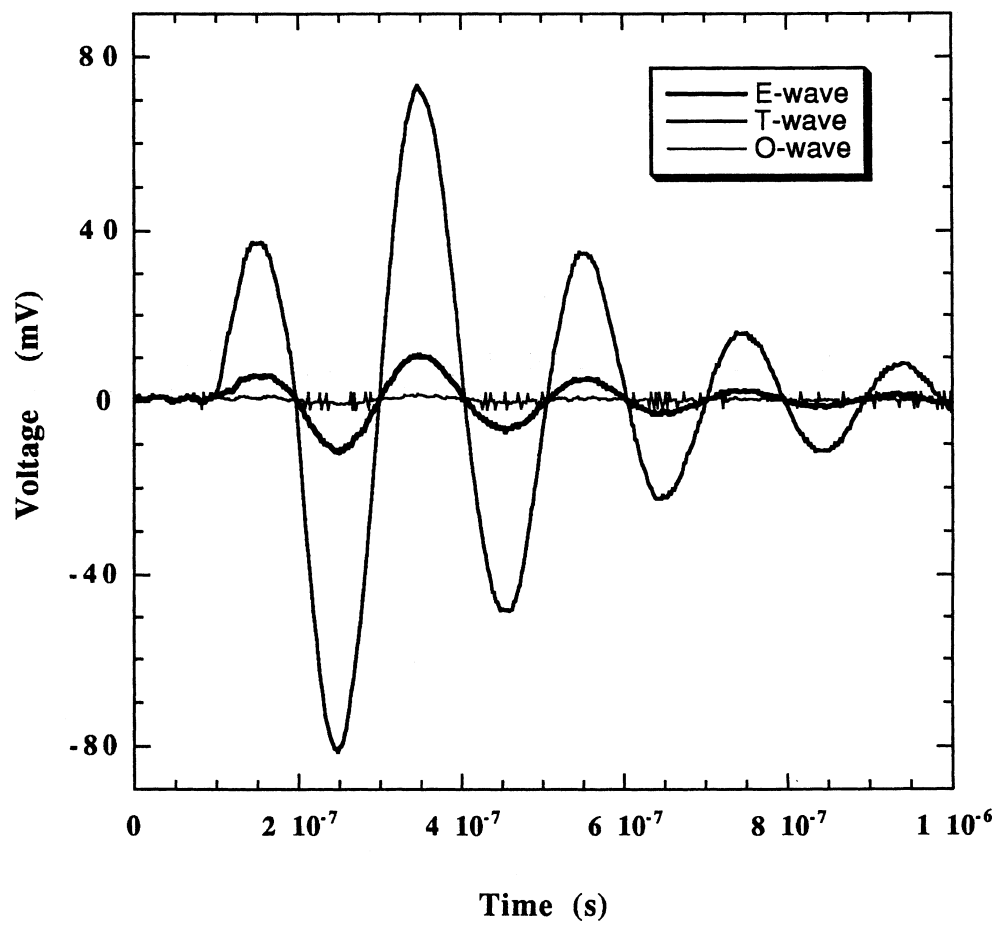

Fig. 5. Acoustic waves acquired in PAC experiments. T-wave: azulene (the calorimetric reference) in toluene, with $A_{660}=0.35$ in a $1 \mathrm{~cm}$ cell; E-wave: TDCPC in toluene with $A_{660}=0.35$ in a $1 \mathrm{~cm}$ cell; O-wave: pure toluene. Irradiation at $660 \mathrm{~nm}$ of aerated toluene solutions, without filters. Average of 100 waves in each case.

a photoacoustic experiment. The acoustic wave generated in the irradiated solution travels across the front-face quartz mirror and reaches the transducer $1.7 \mu \mathrm{s}$ after the laser flash. This is in agreement with the velocity of sound in quartz, $5.90 \times 10^{5} \mathrm{~cm} / \mathrm{s}$, and the thickness of the mirror, $1 \mathrm{~cm}$. The first step of the data analysis consists in multiplying the $\mathrm{O}$-waves by the fraction of light absorbed by the reference (or sample) solution in the photoacoustic cell, in order to obtain the true background signals that affect the T- and E-waves. Then, a pair of T- and E-waves is corrected for the background signal, by subtracting a scaled $\mathrm{O}$-wave, and normalised. The same procedure is repeated for the other three sets of waves. The analysis of the experimental results is based on the four independent sets of background-corrected T- and E-waves measured at the same laser intensity. Fig. 6 illustrates normalised and background-corrected waves obtained in this work. The laser intensity is changed by interposing a filter with transmission in the 30-100\% range, and four new concordant sets of T-, E- and O-waves are acquired. Each PAC experiment consists in the acquisition of four sets of T-, E- and O-waves at four different laser intensities, each one of them resulting from 100 laser shots. At least two PAC experiments were made at each laser line for each porphyrin or chlorin.

The calorimetric reference transforms into heat all the excitation energy in a time shorter than the time resolution of the pressure transducer. Thus, the T-wave is the transducer response to an "instantaneous" heat deposition. The
E-wave is the modulated response of the transducer to pressure changes that approach its ringing frequency. In order to extract information on the lifetime and magnitude of the processes that modulate the transducer response and lead to E-wave, we must deconvolute the E-wave using the T-wave and a kinetic model.

The kinetic scheme employed to deconvolute the photoacoustic waves measured in this work is presented in Fig. 7. The first process measured by PAC is the formation of the triplet state of the sensitiser and the second one is its decay. Thus, we have two-sequential decays, each one described by a lifetime $\left(\tau_{\mathrm{i}}\right)$ and a fraction of energy released in that lifetime $\left(\phi_{\mathrm{i}}\right)$. In principle, the deconvolution can fit these four parameters. However, we reduce the number of adjustable parameters using the singlet state lifetimes of our porphyrins (15.1 ns for TDFPP, $2.2 \mathrm{~ns}$ for ToCPP and $0.22 \mathrm{~ns}$ for TDCPP [2]) and setting $\tau_{1}=1 \mathrm{~ns}$ for chlorins. Our deconvolution of the acoustic waves uses the Marquardt's algorithm to fit $\phi_{1}, \phi_{2}$ and $\tau_{2}$ [30,31]. This method has been described in detail and extensively tested [1,21,22,32]. Although the waves of $\mathrm{N}_{2}$-saturated solutions were fitted with three adjustable parameters $\left(\phi_{1}, \phi_{2}, \tau_{2}\right)$, the triplet lifetime exceeds the time resolution of the $2.25 \mathrm{MHz}$ transducer employed in these photoacoustic studies and gives a meaningless fraction of energy released, $\phi_{2}\left(\mathrm{~N}_{2}\right)$. The only value of interest in these studies is $\phi_{1}$. We work at low laser intensities and unfocused laser beams to minimise biphotonic processes, but they may still occur and contribute to the prompt heat 


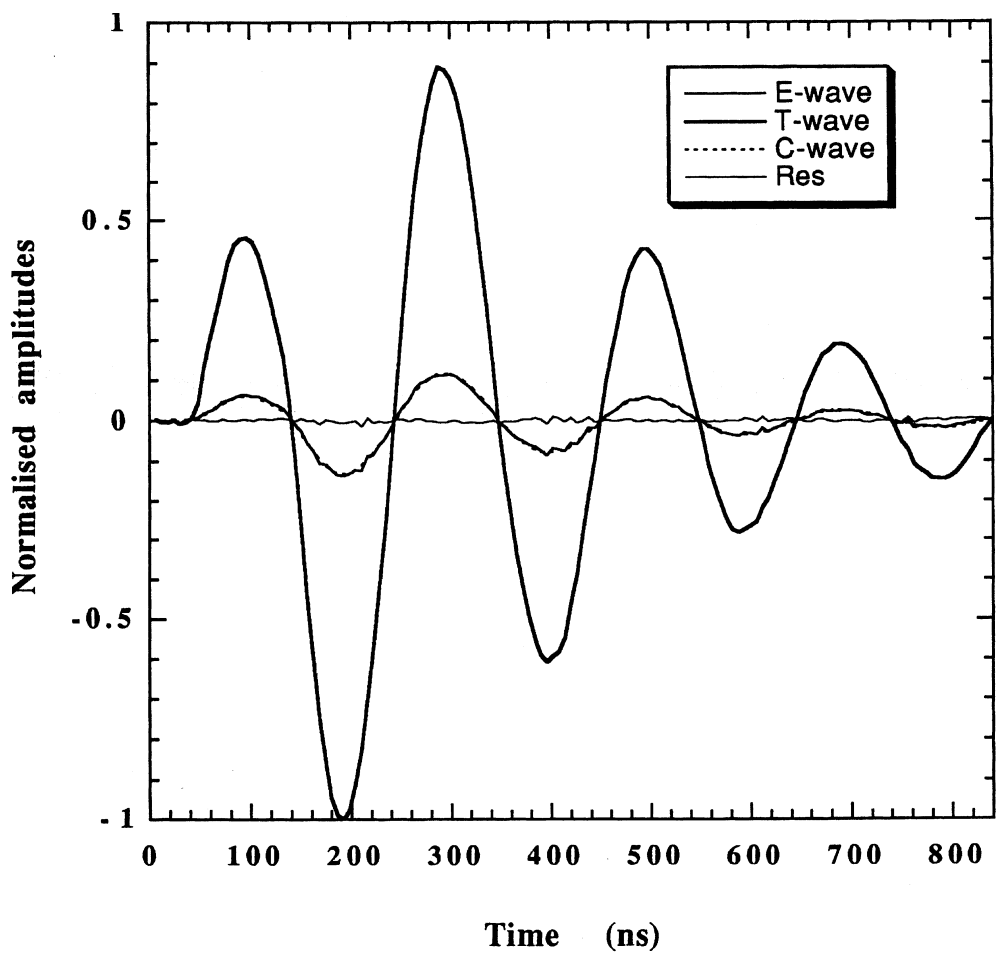

Fig. 6. Normalised and background-corrected T- and E-waves, obtained from the waves shown in Fig. 5. The normalisation factor is the reciprocal of the largest absolute value of the T-wave. The $\mathrm{C}$-wave was obtained convoluting the $\mathrm{T}$-wave with two-sequential exponential decays of lifetimes $\tau_{1}=1 \mathrm{~ns}$ and $\tau_{2}=393 \mathrm{~ns}$ and fractions of heat release $\phi_{1}=0.1312$ and $\phi_{2}=0.0626$. Res $=$ E-wave $-\mathrm{C}$-wave.

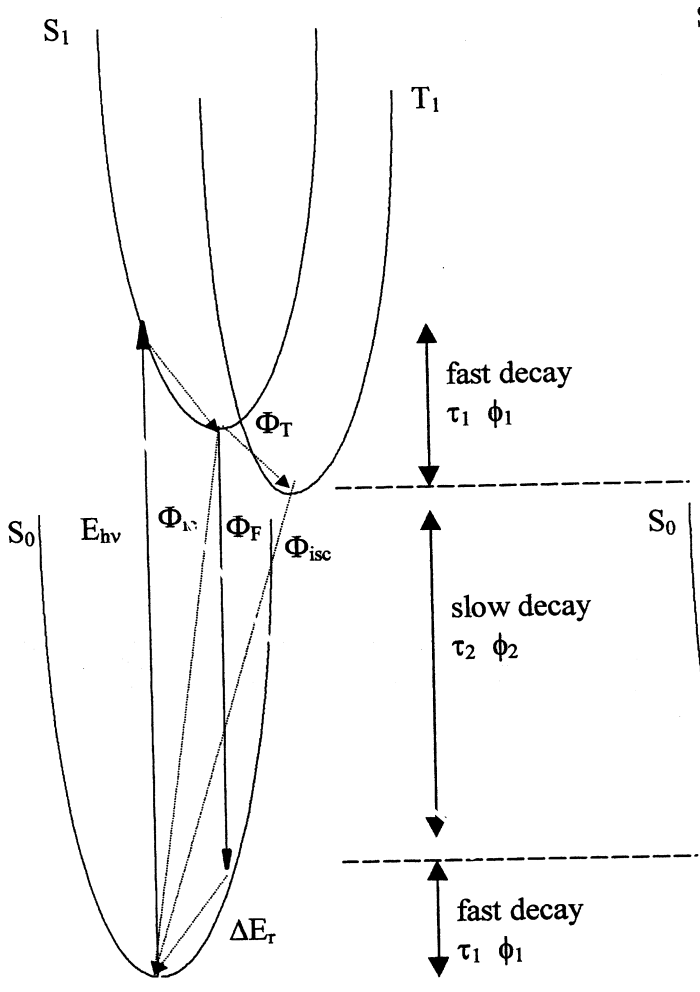

a)

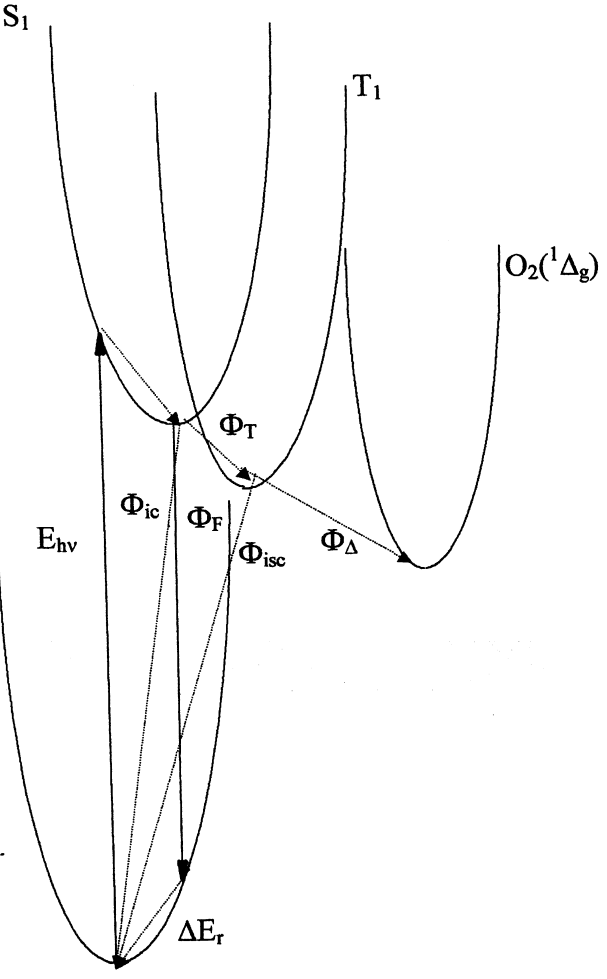

b)

Fig. 7. Photoinduced processes: (a) in the absence and (b) in the presence of molecular oxygen. Full lines: radioactive processes; dashed lines: radiationless processes. $\Delta E_{\mathrm{r}}$ represents the relaxation energy of the ground-state species formed radiatively from the lowest excited singlet state. 


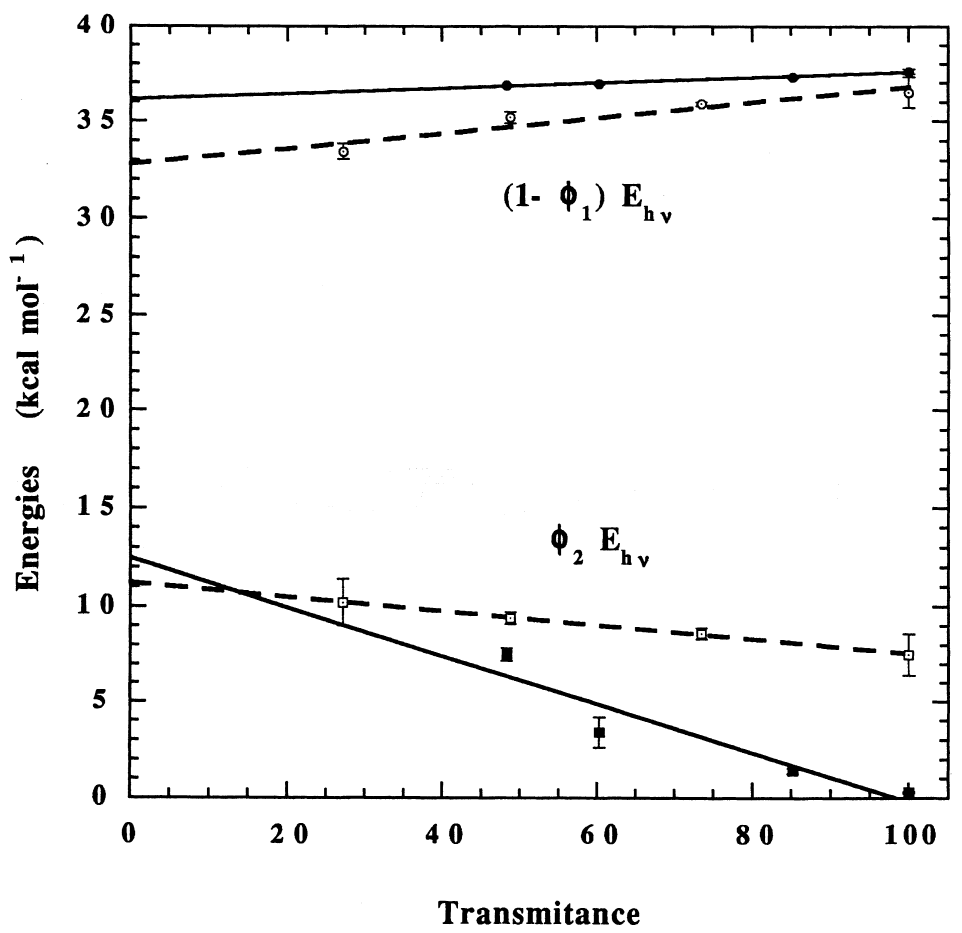

Fig. 8. Laser intensity studies of the heat released in PAC experiments, under the conditions of Fig. 5. The transmittances refer to filters interposed to attenuate the laser intensity. The circles correspond to the heat not released in the fast decay (i.e., the energy stored in the triplet), and were measured in $\mathrm{N}_{2}$-saturated solutions. The squares represent the heat released in the formation of singlet oxygen in air-saturated solutions. Open symbols and dashed lines correspond to irradiation at $421 \mathrm{~nm}$ and closed symbols and full lines refer to irradiation and $660 \mathrm{~nm}$.

release. This can be assessed comparing the values of $\phi_{1}$ obtained at different laser intensities. A typical laser intensity study is shown in Fig. 8. If significant laser intensity dependence is observed, the value of $\phi_{1}$ has to be extrapolated to zero laser intensity. The values of $\phi_{1}$ reported in Table 2 were corrected for their eventual laser intensity dependence.

In air-saturated solutions, $\phi_{2}$ (air) is associated with transfer of energy from the triplet state of the sensitiser to molecular oxygen (Fig. 7(b)). Its decay time, $\tau_{2}$, is established in flash photolysis experiments using air-saturated solutions and kept invariable in the deconvolution of the photoacoustic waves, together with $\tau_{1}$. Thus, in air-saturated solutions only $\phi_{1}$ and $\phi_{2}$ are adjusted to reproduce the E-wave from the T-wave and the two-sequential decays model. The differences between the values of $\phi_{1}$ obtained in $\mathrm{N}_{2}$ - and air-saturated solutions are not statistically significant. The quality of the results can be assessed comparing each calculated wave (C-wave) with the corresponding E-wave. This is shown in Fig. 6. In Table 2 we present the thermal energy released in the first and second decays measured by PAC.

The absorption of the solutions did not change with their irradiation, indicating that the sensitisers did not decompose appreciably during flash photolysis or photoacoustic experiments.

\section{Discussion}

The absorption and emission characteristics of free-base porphyrins and their derivatives are well known [26,33-36]. The effect of peripheral substitution on the optical properties of many free-base and metallated porphyrins was recently reviewed [2]. We observed the expected increase in absorbance of the $\mathrm{Q}_{x}(0-0)$ with the reduction of $\mathrm{D}$ ring. TDFPC and ToCPC absorptions at $655 \mathrm{~nm}$ and the TDCPC absorption at $660 \mathrm{~nm}$ are enhanced relative to the corresponding porphyrins. Halogenation at ortho position of the phenyl ring leads to fluorescence quenching. This is assigned to an increase in the intersystem crossing rate due to a heavy-atom effect. Chlorins are slightly more fluorescent than porphyrins.

The triplet lifetimes are much shorter in air-saturated than in $\mathrm{N}_{2}$-saturated toluene solutions. Table 2 presents the rate constants for singlet oxygen formation estimated from the concentration of molecular oxygen in air-saturated solutions $\left(\left[\mathrm{O}_{2}\right]=1.81 \times 10^{-3} \mathrm{M}\right)$ and the lifetimes measured at room temperature. The oxygen quenching rate constants approach $\frac{1}{9} k_{\mathrm{dif}}=3.4 \times 10^{9} \mathrm{M}^{-1} \mathrm{~s}^{-1}$, as expected for exothermic energy transfers.

The fast thermal energy release, associated with $\tau_{1}$, is due to the formation of the relaxed $S_{1}$ state, followed by the formation of the triplet state (quantum yield $\Phi_{\mathrm{T}}$ ) and by the 
internal conversion to the ground state (quantum yield $\Phi_{\text {IC }}$ ). The ground-state species formed by fluorescence (quantum yield $\Phi_{\mathrm{F}}$ ) also relaxes in this time window and contributes to the thermal energy released in $\tau_{1}$. These contributions are shown in Fig. 7 and can be formulated as [1]

$$
\begin{aligned}
E_{h v} \phi_{1}= & \left(E_{h v}-E_{\mathrm{S}}\right)+\left(E_{\mathrm{S}}-E_{\mathrm{T}}\right) \Phi_{\mathrm{T}} \\
& +E_{\mathrm{S}} \Phi_{\mathrm{IC}}+\Delta E_{\mathrm{r}} \Phi_{\mathrm{F}}
\end{aligned}
$$

Developing this expression and considering that $\Phi_{\mathrm{IC}}=1-$ $\Phi_{\mathrm{T}}-\Phi_{\mathrm{F}}$, we obtain

$\Phi_{\mathrm{T}} E_{\mathrm{T}}=\left(1-\phi_{1}\right) E_{h v}-\Phi_{\mathrm{F}} E_{v \max }$

where $E_{v \max }$ is the energy at the maximum fluorescence intensity, $E_{v \max }=E_{\mathrm{S}}-\Delta E_{\mathrm{r}}$. The triplet quantum yield can only be determined if the triplet energy is known. As mentioned before, we were unable to detect phosphorescence from our halogenated porphyrins and chlorins, thus we can only speculate that their triplet energy should be similar to that of TPP $\left(E_{\mathrm{T}}=33.0 \mathrm{kcal} \mathrm{mol}^{-1}\right)$. Under this assumption, the data in Table 2 indicates that the triplet quantum yields of our species are in the 0.85-1.02 range.

The evaluation of the photosensitisers efficiency is based on singlet oxygen quantum yields $\left(\Phi_{\Delta}\right)$ and not in $\Phi_{\mathrm{T}}$. In air-saturated solutions, $\Phi_{\Delta}$ can be obtained from the fraction of heat released in the formation of the singlet oxygen from the triplet state of the sensitiser. In fact, the slow thermal energy release, associated with $\tau_{2}$, is due to the decay of the triplet state to give singlet oxygen (quantum yield $\Phi_{\Delta}$ ) and to return to the ground state (quantum yield $\Phi_{\text {ISC }}$ ) [1]

$E_{h v} \phi_{2}=\left(E_{\mathrm{T}}-E_{\Delta}\right) \Phi_{\Delta}+E_{\mathrm{T}} \Phi_{\mathrm{ISC}}$

Considering that $\Phi_{\Delta}+\Phi_{\text {ISC }}=\Phi_{\mathrm{T}}$, we have

$\Phi_{\Delta}=\frac{\Phi_{\mathrm{T}} E_{\mathrm{T}}-E_{h \nu} \phi_{2}}{E_{\Delta}}$

Using $E_{\Delta}=22.5 \mathrm{kcal} \mathrm{mol}^{-1}$, we obtain the values of $\Phi_{\Delta}$ shown in Table 2 . It is very clear that $\Phi_{\Delta}$ increases with the atomic number of the halogen substituent and with the number of halogen substituents.

The uncertainties in the singlet oxygen quantum yields measured by us are ca. \pm 0.05 at the $95 \%$ confidence level, as reported in Table 2. Considering that $\Phi_{\mathrm{T}} \geq \Phi_{\Delta}$, the triplet quantum yields of our halogenated porphyrins and chlorins are greater than 0.84 . Triplet quantum yields can also be measured with flash photolysis using the triplet-triplet energy-transfer method [37,38]. However, the accuracy of such studies cannot exceed that of the reference triplet absorptivities, and, at the $95 \%$ confidence level, these are rarely known to better than 5\%. Thus, the energy-transfer method does not provide additional information on our systems.

\section{Conclusions}

Chlorinated chlorins store sufficient electronic energy for a sufficiently long time to sensitise the formation of singlet oxygen with unit efficiency. Their absorptivities at $640 \mathrm{~nm}$ are ca. 10 times larger than those of porphyrins and $\mathrm{HpD}$. Moreover, they are photostable and do not react with singlet oxygen in the time scale of our photoacoustic experiments $(1 \mu \mathrm{s})$. Thus, from the photochemical point of view, chlorinated chlorins are interesting PDT sensitisers. These chlorins do not have the solubility required for PDT experiments, but there are suitable templates for the introduction of hydroxyl and sulphonamide or sulphonic ester substituents that may modulate their solubility. Work along these lines is in progress in our laboratory.

\section{Acknowledgements}

Fundação para a Ciência e Tecnologia provided financial support. M. Pineiro received a scholarship from PRAXIS XXI/BD/11398/97.

\section{References}

[1] M. Pineiro, A.L. Carvalho, M.M. Pereira, A.M.d'A.R. Gonsalves, L.G. Arnaut, S.J. Formosinho, Chem. Eur. J. 4 (1998) 2299.

[2] S.I. Yang, J. Seth, J.-P. Strachan, S. Gentemann, D. Kim, D. Holten, J.S. Lindsey, D.F. Bocian, J. Porphyrins Phthalocyanines 3 (1999) 117.

[3] R. Bonnett, P. Charlesworth, B.D. Djelal, D.J. McGarvey, T.G. Truscott, J. Chem. Soc., Perkin Trans. 2 (1999) 325.

[4] J.D. Spence, T.D. Lash, J. Org. Chem. 65 (2000) 1530.

[5] A.J. Hudson, T. Richardson, J.P. Trirtle, R.A.W. Johnstone, A.J.F.N. Sobral, A.M.d'A.R. Gonsalves, Mol. Cryst. 253 (1993) 103.

[6] M.B. Grieve, T. Richardson, R.A.W. Johnstone, A.F.N.L. Sobral, A.M.d'A.R. Gonsalves, Thin Solid Films 243 (1994) 581.

[7] A.M.d'A.R. Gonsalves, M.M. Pereira, J. Mol. Catal. A 113 (1996) 209.

[8] T.J. Dougherty, Photochem. Photobiol. 45 (1987) 879.

[9] T.J. Dougherty, Adv. Photochem. 17 (1992) 275.

[10] T.J. Dougherty, Photochem. Photobiol. 58 (1993) 895.

[11] R. Bonnett, Chem. Soc. Rev. 24 (1995) 19.

[12] C. Abels, A.E. Goezt, in: H. Hönidsmann, G. Jori, A.R. Young (Eds.), The Fundamental Bases of Phototherapy, OEMF spa, Milano, 1996, p. 265.

[13] A.F. Mironov, A.S. Seylanov, J.A. Seylanov, V.M. Pizhik, I.V. Derughenko, A. Ju Nockel, J. Photochem. Photobiol. B 16 (1992) 341.

[14] G. Jori, J. Photochem. Photobiol. A 62 (1992) 371.

[15] R. Bonnett, R.D. White, U.-J. Winfield, M.C. Berenbaum, Biochem. J. 261 (1989) 277.

[16] M. Shopova, V. Mantavera, K. Krastev, D. Hadjiolov, A. Milev, K. Spirov, G. Jori, F. Riccheli, J. Photochem. Photobiol. B 16 (1992) 83.

[17] E.D. Sternberg, D. Dolphin, C. Brucker, Tetrahedron 54 (1998) 4151.

[18] F.-P. Montforts, N. Gerlach, F. Höper, Chem. Rev. 94 (1994) 327.

[19] F.-P. Montforts, M. Glasenapp-Breiling, Prog. Heterocyclic Chem. 10 (1998) 1.

[20] L.G. Arnaut, R.A. Caldwell, J.E. Elbert, L.A. Melton, Rev. Sci. Instrum. 63 (1992) 5381.

[21] S. Seixas de Melo, L.M. Silva, L.G. Arnaut, R.S. Becker, J. Chem. Phys. 111 (1999) 5427. 
[22] C. Serpa, L.G. Arnaut, J. Phys. Chem. 104 (2000) 11075.

[23] C.A. Parker, T.W. Rees, Analyst 85 (1960) 587.

[24] A.M.d'A.R. Gonsalves, J.M.T.B. Varejão, M.M. Pereira, J. Heterocyclic Chem. 28 (1991) 635.

[25] H.W. Whitlock Jr., R. Hanauer, M.Y. Oester, B.K. Bower, J. Am. Chem. Soc. 91 (1969) 7485.

[26] M. Gouterman, in: D. Dolphin (Ed.), The Porphyrins, Vol. 3, Academic Press, New York, 1978, p. 1.

[27] A. Harriman, J. Chem. Soc., Faraday I 76 (1980) 1978.

[28] J.B. Birks, Chem. Phys. Lett. 17 (1972) 370.

[29] J.R. Andrews, R.M. Hochstraser, Chem. Phys. Lett. 76 (1980) 207.

[30] L.A. Melton, T. Ni, Q. Lu, Rev. Sci. Instrum. 60 (1989) 3217.
[31] T. Ni, R.A. Caldwell, L.A. Melton, J. Am. Chem. Soc. 111 (1989) 457.

[32] L.G. Arnaut, R.A. Caldwell, J. Photochem. Photobiol. A 65 (1992) 15.

[33] C. Weiss, H. Kobayashi, M. Gouterman, J. Mol. Spectrosc. 16 (1965) 415.

[34] J.C. Weiss, J. Mol. Spectrosc. 44 (1972) 37.

[35] M. Gouterman, J. Chem. Phys. 30 (1959) 1139.

[36] M. Gouterman, G.H. Wagnière, L.C. Snyder, J. Mol. Spectrosc. 11 (1963) 108.

[37] R. Bensasson, C.R. Goldschmidt, E.J. Land, T.G. Truscott, Photochem. Photobiol. 28 (1978) 277.

[38] I. Carmichael, G.L. Hug, J. Phys. Chem. Ref. Data 15 (1986) 1. 